\title{
The Geography of Need: Spatial Distribution of Barriers to Employment in Metropolitan Detroit
}

\author{
Scott W. Allard, Richard M. Tolman, and Daniel Rosen
}

Although several studies examine the barriers to employment that limit the employability of welfare recipients, they have not analyzed how these barriers might be different for residents of central cities than for residents in surrounding suburban areas. We consider how the prevalence of barriers to employment varies by race and place in metropolitan Detroit. We find that the prevalence of mental health, substance abuse, and domestic violence barriers is higher in suburban areas, and that structural barriers are higher in the central city.

The time-limited, work-oriented welfare policies mandated by the Personal Responsibility and Work Opportunity Reconciliation Act of 1996 (PRWORA) have brought greater attention to the factors that affect work activity among welfare recipients. ${ }^{1}$ Recent studies have examined the barriers to employment experienced by many welfare recipients as they participate in welfare-to-work programs and work search activity (Goldberg, 2002; Zedlewski \& Alderson, 2001). Some human capital barriers to employment, such as having few job skills, little work experience, or low levels of education, have long been recognized as obstacles to finding and retaining employment. The presence of physical limitations or disabilities, mental health problems, substance use or abuse, and domestic violence, all of which have been found to be related to lower work outcomes, typically have received less attention (Danziger et al., 2000). Structural barriers, such as lack of job access, also affect whether welfare recipients are able to find work and exit welfare (Allard \& Danziger, 2003).

Most research examining barriers to employment does not examine whether the prevalence of barriers varies by geographic location. The presence of spatial variation in the prevalence of barriers to employment, however, would have important implications for the delivery of social services, as well as for welfareto-work outcomes. In this study, we consider how the prevalence of different barriers varies across metropolitan Detroit, Michigan. To do so, we examine data on 
barriers from the Mothers' Well-Being Study (MWS), a 1999 survey of TANF recipients in Detroit and its surrounding suburbs. The MWS gathered detailed information on issues relating to human capital, mental health, substance abuse, and domestic violence. To this MWS data, we link job accessibility measures from two employer surveys that capture proximity to employment opportunities in Detroit in the late 1990s and reflect structural barriers to employment. Combined, these data allow us to examine how the prevalence of different barriers to employment varies across the urban geography of metropolitan Detroit. Because Detroit is similar to many other older industrial metro areas and because MWS respondents are representative of welfare recipients in the late 1990s, our findings should be relevant to a broader population.

This article proceeds as follows. First, we briefly discuss the relationship between barriers to employment and work. Next, we describe our data. Third, we consider how the prevalence of these barriers among welfare recipients varies by race and across central city/suburban Detroit. We then examine the co-occurrence of various barriers to employment across race and place. Finally, we conclude with implications of our findings for policy and for future research.

\section{Barriers to Employment Among Welfare Recipients}

The Personal Responsibility and Work Opportunity Reconciliation Act of 1996 (PRWORA) marked a dramatic shift in the provision of assistance to welfare recipients. Not only are those receiving assistance through the Temporary Assistance for Needy Families (TANF) program now expected to pursue work activity for at least 30 hours per week, but recipients are limited to 60 months of assistance in their lifetimes. Recent research demonstrates that many participants in welfare-to-work programs experience a number of barriers to employment, which hamper their efforts to find and retain a job (Danziger et al., 2000). In a time-limited, work-oriented system, therefore, these barriers pose significant challenges for policymakers and program managers.

Some barriers to employment, such as few job skills, little work experience, or low levels of education, are commonly recognized human capital factors (Allard \& Danziger, 2003; Danziger \& Seefeldt, 2002). Other welfare recipients face structural barriers to employment, such as poor access to job opportunities or isolation from areas with low-skill job growth (Allard, 2002; Holzer \& Stoll, 2001). Further, welfare recipients experience poor physical health and food insecurity at rates higher than in the general population (Polit, London, \& Martinez, 2001). Poor women and welfare mothers are at high risk for mental health problems (Danziger et al., 2000; Jayakody \& Stauffer, 2000; Lennon, Blome, \& English, 2001; Lutenbacher, 2000); and substance abuse and dependence are at least as prevalent among welfare recipients as among the general population (Danziger et al., 2000; Grant \& Dawson, 1996; Jayakody, Danziger, \& Pollack, 2000). Lifetime and 12-month prevalence rates of domestic violence for 
welfare recipients are considerably higher than national levels (Tolman \& Raphael, 2000). A number of studies have documented both direct interference in work activities by abusers (Allard, Albeida, Colten, \& Cosenza, 1997; Barusch, Taylor, Derr, \& Abu-Bader, 1999; Tolman \& Rosen, 2001) and increased levels of physical and mental health problems among domestic violence victims that could impede work success (Browne, Solomon, \& Bassuk, 1999; Tolman \& Rosen, 2001).

Whether relating to human capital, access to opportunities, physical health, mental health, or domestic violence, there is mounting evidence that the presence of one or several barriers to employment for welfare recipients reduces their number of work outcomes (Danziger et al., 2000; Kalil, Schweingruber, \& Seefeldt, 2001; Tolman \& Raphael, 2000; U.S. General Accounting Office, 2002a). It is not surprising, therefore, that a significant amount of welfare-to-work program resources are targeted at support services intended to help welfare recipients overcome barriers (U.S. General Accounting Office, 2002b). Despite discussion of the prevalence of barriers to employment among low-income women and the growing emphasis on services to address them, however, there is little research examining how such barriers are spatially distributed. Identifying spatial variation in barriers to employment should encourage us to reexamine more precisely how we deliver social services. Further, spatial variation in barriers should help to explain what might be driving observed geographic variation in welfareto-work outcomes.

\section{Data and Methodology}

To examine whether barriers to employment among welfare recipients vary geographically, we analyze data drawn from the MWS, a random sample of 668 welfare recipients, conducted in the Detroit metropolitan area in 1999. When properly weighted, the MWS data are generalizable to the 1999 welfare caseload in the three-county Detroit metropolitan area. The MWS asked respondents questions about recent employment, welfare receipt, transportation, residential location, mental health conditions, alcohol and substance use, and domestic violence. ${ }^{2}$ We geocoded information on the residential location of respondents to indicate the Census tract of residence.

To reflect whether welfare recipients had experienced a mental health disorder in the year prior to the survey, the MWS administered the World Health Organization Composite International Diagnostic Interview version 2.1 (WHO-CIDI-2.1), a standard measure of psychiatric disorders designed to be used by lay interviewers. Respondents experiencing any of the following mental health disorders in the past 12 months were coded as having a mental health barrier: major depression, dysthymia, social anxiety disorder, simple phobias, panic disorder, agoraphobia, and post-traumatic stress disorder. ${ }^{3}$ The WHO-CIDI also included measures of alcohol and drug abuse and dependence. Those respondents 
indicating abuse of drugs or alcohol in the 12 months prior to the survey were coded as having a substance abuse barrier. To measure domestic violence, we determined if a respondent had experienced any of the following types of physical abuse from a male partner in the previous 12 months: pushed, grabbed, shoved, slapped, kicked, hit with a fist, slammed against a wall, beaten, choked, or threatened with a knife or gun. ${ }^{4}$ We also created a two-item interference with work scale: either staying home from work or school because of something a partner did or being harassed/interfered with at work, school, or training by a partner. We focused on two nonhealth barriers to employment: no access to an automobile and conviction of a crime. Respondents were asked whether they owned or had regular use of a car, and they were asked if they had ever been convicted of a crime during their lifetimes.

To ascertain the prevalence of structural barriers to employment, we created two job accessibility measures for each residential Census tract in the Detroit metropolitan area from the 1992 and 1997 employer surveys: (1) access to all employment opportunities in 1997 and (2) the change in access to all job opportunities between 1992 and 1997. ${ }^{5}$ Our job access measures should be interpreted as follows. For our measure of job access in 1997, a welfare recipient living in a tract with an access score of 1.10 resides in proximity to $10 \%$ more jobs per adult than does the resident of the tract with the mean access score; a recipient living in a tract with an access score of 0.90 resides in proximity to $10 \%$ fewer jobs per adult than a resident of the mean tract. For our measure of change in job accessibility between 1992 and 1997, a score of 0.10 would correspond to a $10 \%$ increase in overall job access compared with the mean metropolitan tract. Since there are over 2.5 million jobs in the Detroit metropolitan area, even small shifts in our access scores will reflect important differences in access to employment.

For the purposes of this study, we consider the Detroit metropolitan area to comprise Wayne, Oakland, and Macomb counties in southeastern Michigan. The City of Detroit rests in the eastern corner of Wayne County, with the largely suburban counties of Oakland and Macomb lying to the northwest and northeast of Wayne County, respectively. Detroit is typical of many large cities with a high poverty urban core and a lower poverty suburban periphery (see Figure 1). According to the 2000 Census, the female unemployment rate in the City of Detroit was $12.4 \%$, nearly twice that for the metropolitan area overall (5.8\%) and roughly 3 times as high as that in Oakland County (3.7\%) and Macomb County (3.9\%). The poverty rate for the City of Detroit in 2000 was $26.1 \%$, compared with $16.9 \%$ in Wayne County, $5.6 \%$ in Macomb County, and 5.5\% in Oakland County. Consistent with these patterns, Allard (2002) found that about $76 \%$ of all welfare recipients in the metropolitan area in February 2000 lived within the City of Detroit and 90\% of these recipients were African American. As Figure 1 shows, however, pockets of poverty exist in the suburban areas of metropolitan Detroit, particularly in southern Wayne County and in the City of Pontiac in Oakland County. 


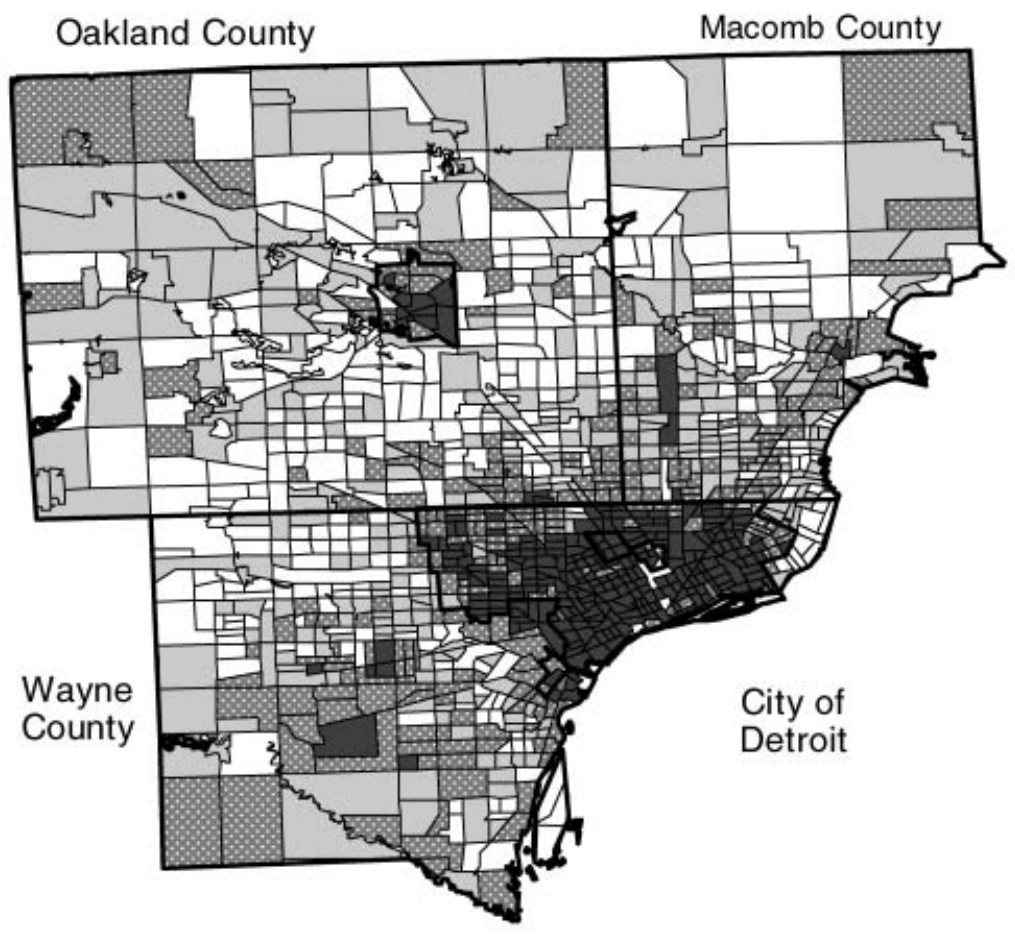

\section{Percentage of Individuals Below Poverty Line

\begin{tabular}{|l|l|}
\hline & $3 \%$ or less \\
3 & 3 to $6 \%$ \\
6 & to $19 \%$ \\
$19 \%$ & or more \\
\hline
\end{tabular}

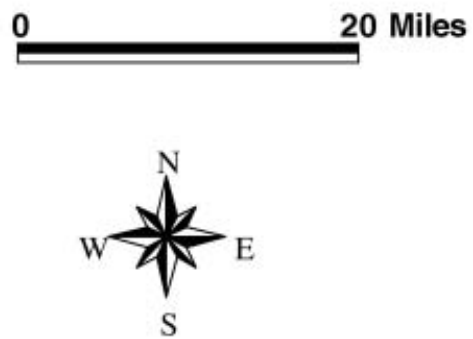

Figure 1. Census Tract Poverty Rates in Metropolitan Detroit, 2000.

\section{Barriers to Employment at the Metropolitan Level}

We report the prevalence of these barriers to work across MWS respondents in Table $1 .{ }^{6}$ Mental health barriers are common-39.2\% of MWS respondents met diagnostic screening criteria for a mental health problem in the 12 months prior to the survey. Roughly $7 \%$ experienced some type of alcohol or drug problem in the 12 months prior to the survey, and $13.9 \%$ experienced domestic violence and $4.6 \%$ encountered partner interference in work activities. 
Table 1. Barriers to Employment

\begin{tabular}{|c|c|c|c|}
\hline Barrier to employment & $\begin{array}{l}\text { Total MWS } \\
\text { sample }\end{array}$ & Whites & $\begin{array}{c}\text { African } \\
\text { Americans }\end{array}$ \\
\hline $\begin{array}{l}\text { Mental health problem: Presence of anxiety, affective, } \\
\text { and posttraumatic stress disorders in Previous Twelve } \\
\text { Months }\end{array}$ & 39.2 & $45.3 *$ & $37.7 *$ \\
\hline $\begin{array}{l}\text { Alcohol/Substance abuse: Presence of alcohol or drug } \\
\text { disorder in Previous Twelve Months }\end{array}$ & 6.7 & 7.7 & 6.5 \\
\hline $\begin{array}{l}\text { Domestic violence: Report being pushed, grabbed, } \\
\text { shoved, slapped, kicked, hit with a fist, slammed } \\
\text { against a wall, beaten, choked, or threatened with a knife } \\
\text { or gun in Previous Twelve Months }\end{array}$ & 13.9 & 11.8 & 14.4 \\
\hline $\begin{array}{l}\text { Work interference: Report any spousal or partner } \\
\text { interference in work, education, or training activities in } \\
\text { Previous Twelve Months }\end{array}$ & 4.6 & $9.3 * *$ & $3.5 * *$ \\
\hline $\begin{array}{l}\text { Percentage with below average access to jobs: Less } \\
\text { proximity to job opportunities in } 1997 \text { than the average } \\
\text { residential tract }\end{array}$ & 79.9 & $57.4 * *$ & $85.3 * *$ \\
\hline $\begin{array}{l}\text { Percentage with a loss in access to jobs: Declining access } \\
\text { to jobs between } 1992 \text { and } 1997\end{array}$ & 87.7 & $67.8 * *$ & $92.4 * *$ \\
\hline $\begin{array}{l}\text { Percentage without access to an automobile: Report no } \\
\text { household access to an automobile }\end{array}$ & 39.8 & $18.8 * *$ & $44.8 * *$ \\
\hline $\begin{array}{l}\text { Percentage convicted of a crime: Report a past conviction } \\
\text { for a crime }\end{array}$ & 8.3 & $14.8 * *$ & $6.7 * *$ \\
\hline Unweighted $N$ & 668 & 273 & 390 \\
\hline
\end{tabular}

Note: Reported percentages are weighted using the MWS sample survey weights.

*Difference of means between Whites and African Americans is significant at the 0.10 level or below.

**Difference of means between Whites and African Americans is significant at the 0.05 level or below.

Source: MWS Survey.

Nearly $80 \%$ of all MWS respondents were living in residential Census tracts with less job access than the average metropolitan tract. ${ }^{7}$ Between 1992 and 1997, almost $90 \%$ of MWS respondents lived in residential tracts that had experienced a decline in job access. ${ }^{8}$ The bottom portion of Table 1 considers access to an automobile and whether a respondent had been convicted of a crime. Almost $40 \%$ of all MWS respondents reported not having access to an automobile, and less than $10 \%$ indicated they had been convicted of some type of crime.

The last two columns in Table 1 reflect how the prevalence of different barriers to employment varies between Whites and African Americans in the MWS. Whites were slightly more likely to have experienced a mental health problem in the 12 months prior to the survey than were African Americans (45.3\% versus $37.7 \%$, respectively). Although there was no statistically significant race differences in the rates of domestic violence, Whites were nearly 3 times more likely than African Americans to experience work interference (9.3\% versus 3.5\%, 
respectively). Nevertheless, African Americans in the MWS were more likely to live in residential areas with poor and/or declining job accessibility in the 1990s than were Whites. Further, although about half of all African American respondents in the MWS lacked access to an automobile, less than $20 \%$ of whites in the MWS report the same. Finally, the percentage of Whites in the MWS reporting a criminal conviction is more than twice that of African Americans (14.8\% versus $6.7 \%$, respectively).

\section{The Spatial Distribution of Barriers to Employment}

Tables 2 and 3 examine the intercounty differences and intracounty racial differences in the prevalence of barriers to employment in the MWS. The top panel in Table 2 indicates that mental health and substance abuse problems were more prevalent among welfare recipients in suburban areas than in the City of Detroit. For example, column 2 shows that respondents in both Macomb and Oakland Counties had higher rates of substance abuse problems $(19.7 \%$ and $16.4 \%$, respectively) than the City of Detroit (5.3\%). Similarly, the last two columns in Table 2 indicate that respondents from suburban areas were more likely to report domestic violence than respondents from central cities. For instance, one-third of MWS respondents in Macomb County reported any domestic violence in the pre-

Table 2. Weighted Percentage of MWS Respondents Experiencing Barriers To Employment in Previous Twelve Months

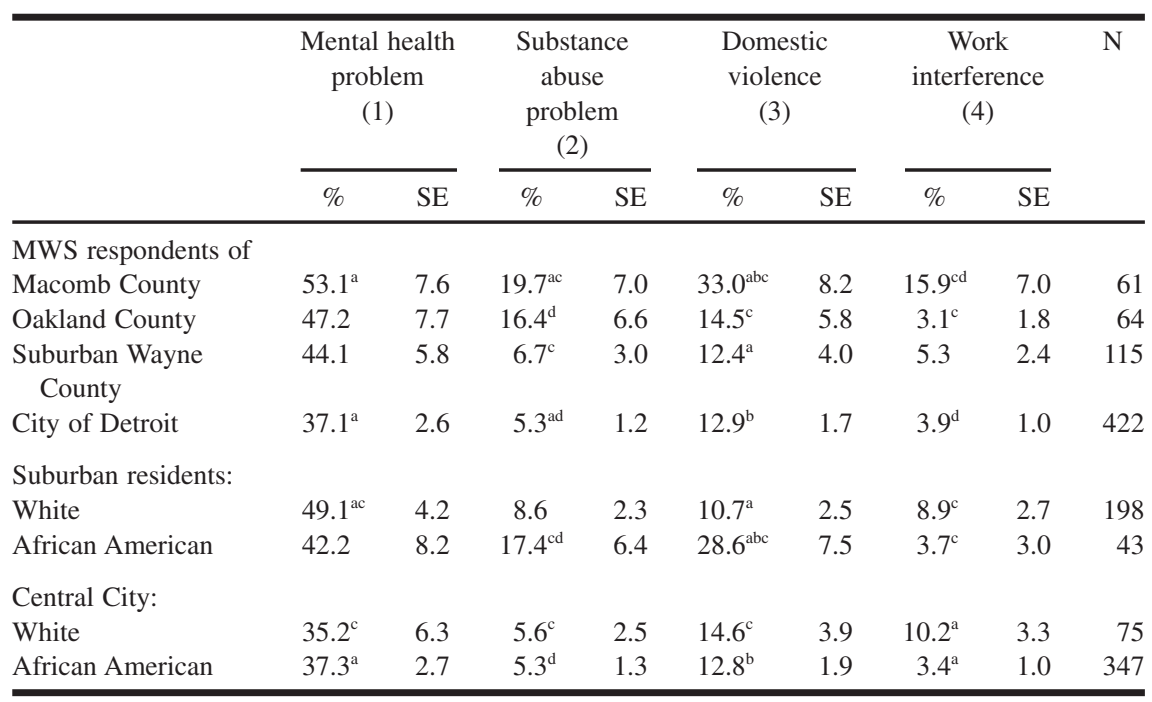

Note: Unweighted N's are given. Reported percentages are weighted using the MWS sample survey weights. ${ }^{a, b}$ Difference of means between two locations is significant at the 0.05 level or below. ${ }^{\mathrm{c}, \mathrm{d}}$ Difference of means between two locations is significant below 0.10 level.

Source: MWS Survey. 
Table 3. Weighted Percentage of MWS Respondents Experiencing Barriers To Employment in Previous Twelve Months

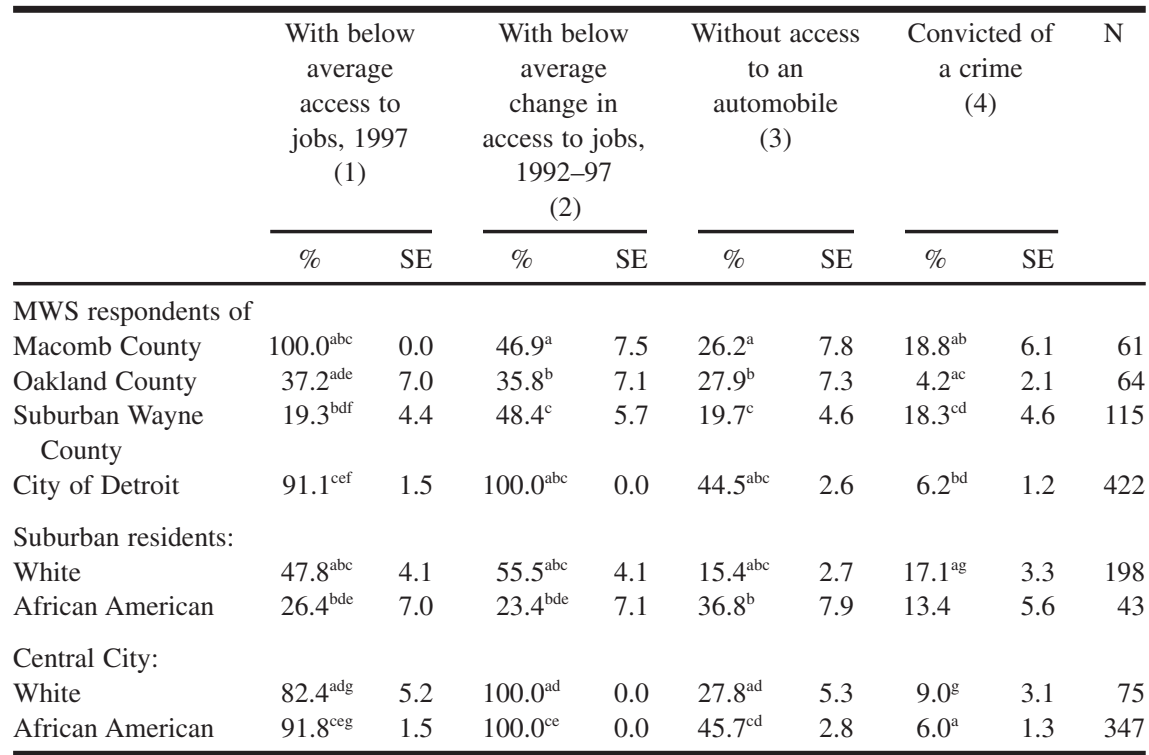

Note: Unweighted $N$ 's are given. Reported percentages are weighted using the MWS sample survey weights. ${ }^{a, b, c, d, e, f}$ Difference of means between two locations is significant at the 0.05 level or below. ${ }^{g}$ Difference of means between two locations is significant below 0.10 level.

Source: MWS Survey.

vious 12 months, more than twice the rate in any other portion of the Detroit metropolitan area (column 3). MWS respondents in Macomb County were at least 3 times more likely to experience work interference than respondents from other portions of the metro area (column 4).

Prevalence rates of abuse also vary by race in suburban and central city areas. For example, the middle panel of Table 2 shows that suburban Whites were more likely to experience mental health problems than Whites in the central city (49.1\% versus $35.2 \%$, respectively). African Americans living in suburban areas were almost 3 times as likely to experience domestic violence as their suburban White counterparts (28.6 versus $10.7 \%$, respectively). Further, Whites in both suburban and central city areas were more likely to report experiencing work interference than were African Americans living in suburban and central city areas. ${ }^{9}$

Columns 1 and 2 of Table 3 examine how structural barriers to employment vary across place and race in the Detroit metropolitan area. In the time period covered by the study, almost all MWS respondents in Macomb County and the City of Detroit lived in neighborhoods with access to fewer jobs than the mean metropolitan Census tract, yet fewer than $20 \%$ of MWS respondents in suburban Wayne County resided in such areas (column 1). Table 3 also indicates that recip- 
ients in the City of Detroit were more likely to live in areas experiencing declining access to jobs compared with their suburban counterparts. For instance, whereas roughly one-third to one-half of suburban respondents experienced a decline in job access during the late 1990s, all respondents in the City of Detroit experienced a decline in job accessibility (column 2). While these findings are consistent with existing research on job access in metropolitan areas, there is interesting intrajurisdictional racial variation in job accessibility. ${ }^{10}$ In particular, the middle panel of Table 3 indicates that although the percentages vary, White MWS respondents who lived in suburban areas were more likely to live in residential tracts with low or declining job access than were African Americans living in suburban areas.

Other factors identified by previous research as having an effect on employment outcomes among welfare recipients also appear to vary by urban geography. Column 3 in Table 3 demonstrates that automobile access varied between central city and suburban locations. For instance, $44.5 \%$ of MWS respondents living in the City of Detroit recipients did not have access to an automobile, yet fewer than $30 \%$ of suburban respondents lacked automobile access. Consistent with metropolitan-wide rates of automobile access, African American respondents in all portions of the metropolitan area were less likely than Whites to have access to a car. Column 4 in Table 3 also reveals that reported rates of criminal conviction from this sample of welfare recipients were much higher in suburban Macomb and Wayne Counties than in the City of Detroit or Oakland County.

Research shows that the presence of multiple barriers or co-occurring barriers to employment can have a particularly negative effect on the work outcomes of welfare recipients (Danziger et al., 2000). Not only is it important to identify how the prevalence of different individual-level and structural barriers to employment varies across urban geography but it is important to understand patterns in the co-occurrence of these barriers. To examine co-occurrence of barriers, we determined how many of seven different barriers were experienced by each MWS respondent in the 12 months prior to the survey: mental health; substance abuse; any physical abuse; work interference; less-than-average access to all job opportunities in 1997; no access to an automobile; and conviction of a crime. Table 4 examines the prevalence of co-occurrent barriers across place and race in metropolitan Detroit.

The first column in the upper panel of Table 4 indicates that a significantly higher percentage of MWS respondents in suburban Oakland and Wayne Counties did not experience any barriers to employment in the 12 months prior to the survey, compared with respondents in Macomb County or the City of Detroit. For example, whereas $1.6 \%$ of recipients in the City of Detroit did not experience any of the seven specified barriers to employment, $18.8 \%$ of respondents in Oakland County and $23.6 \%$ of respondents in suburban Wayne County did not experience any barriers. Similar patterns are manifest in the bottom panels of Table 4, where we compare the co-occurrence of barriers across White and African American 
Table 4. Weighted Percentage of MWS Respondents Experiencing Cooccurring Barriers To Employment in Previous Twelve Months

\begin{tabular}{|c|c|c|c|c|c|c|c|c|c|}
\hline & \multicolumn{2}{|c|}{$\begin{array}{l}\text { No barriers } \\
\text { (1) }\end{array}$} & \multicolumn{2}{|c|}{$\begin{array}{l}1 \text { to } 2 \text { barriers } \\
\text { (2) }\end{array}$} & \multicolumn{2}{|c|}{$\begin{array}{c}3 \text { to } 4 \text { barriers } \\
\text { (3) }\end{array}$} & \multicolumn{2}{|c|}{$\begin{array}{c}5 \text { or more } \\
\text { barriers } \\
\text { (4) }\end{array}$} & \multirow[t]{2}{*}{$\mathrm{N}$} \\
\hline & $\%$ & SE & $\%$ & SE & $\%$ & SE & $\%$ & SE & \\
\hline $\begin{array}{l}\text { MWS respondents of } \\
\text { Macomb County }\end{array}$ & $0.0^{\mathrm{abc}}$ & 0.0 & $52.3^{\mathrm{a}}$ & 7.8 & $33.4^{\mathrm{ab}}$ & 7.4 & $14.3^{\mathrm{f}}$ & 6.8 & 61 \\
\hline Oakland County & $18.8^{\text {ad }}$ & 6.0 & 64.7 & 7.5 & $14.5^{\mathrm{a}}$ & 5.8 & $2.1^{\mathrm{fg}}$ & 1.5 & 64 \\
\hline $\begin{array}{l}\text { Suburban Wayne } \\
\text { County }\end{array}$ & $23.6^{\text {be }}$ & 4.8 & 65.0 & 5.4 & $8.3^{\mathrm{bc}}$ & 3.1 & 3.2 & 1.3 & 115 \\
\hline City of Detroit & $1.6^{\text {cde }}$ & 0.7 & $70.6^{\mathrm{a}}$ & 2.4 & $22.5^{\mathrm{c}}$ & 2.2 & $5.3^{\mathrm{g}}$ & 1.2 & 422 \\
\hline Total MWS sample & 5.1 & & 68.8 & & 20.9 & & 5.2 & & \\
\hline $\begin{array}{l}\text { Suburban residents: } \\
\text { White }\end{array}$ & $16.4^{\mathrm{ab}}$ & 2.8 & 64.0 & 3.9 & $14.9^{\mathrm{a}}$ & 3.0 & 4.7 & 1.4 & 198 \\
\hline African American & $18.5^{\mathrm{c}}$ & 6.6 & 60.3 & 5.9 & 15.5 & 5.7 & 5.7 & 3.9 & 43 \\
\hline Central City: & & & & & & & & & \\
\hline White & $6.4^{\mathrm{a}}$ & 4.2 & 70.0 & 8.1 & 19.2 & 4.5 & 4.4 & 2.2 & 75 \\
\hline African American & $1.3^{\mathrm{bc}}$ & 0.6 & 70.7 & 2.5 & $22.8^{\mathrm{a}}$ & 2.3 & 5.3 & 1.3 & 347 \\
\hline
\end{tabular}

Note: Unweighted $N$ 's are given. Reported row percentages are weighted using the MWS sample survey weights. ${ }^{\mathrm{a}, \mathrm{b}, \mathrm{c}, \mathrm{d}, \mathrm{e}}$ Difference of means between two locations is significant at the 0.05 level or below. ${ }^{\mathrm{f}, \mathrm{g}}$ Difference of means between two locations is significant below 0.10 level.

Source: MWS Survey.

welfare recipients living in suburban and central city areas. For instance, column 1 in the bottom panel of Table 4 shows that White and African American suburban recipients were more likely not to be experiencing any of the seven specified barriers to employment than were recipients living in the central city.

Consistent with these findings, columns 3 and 4 in the upper panel of Table 4 show that MWS respondents in Macomb County and the City of Detroit were much more likely than respondents in Oakland and suburban Wayne Counties to experience three or more co-occurring barriers. Recipients in Macomb County were more than twice as likely to experience three to four barriers as recipients in Oakland County (33.4\% versus $14.5 \%$, respectively). Recipients in the City of Detroit were almost 3 times more likely to experience three to four barriers than recipients in the neighboring areas of suburban Wayne County (22.5\% versus $8.3 \%$, respectively).

\section{Conclusion}

We find spatial variation in the prevalence of barriers to employment experienced by welfare recipients across the Detroit metropolitan area. The prevalence of mental health, substance abuse, and domestic violence barriers to employment 
was higher among welfare recipients in suburban areas, whereas welfare recipients living in the central city of Detroit were more likely to experience structural barriers to employment. Moreover, there is evidence that suburban welfare recipients experiencing mental health and substance abuse barriers to employment lived farther from job opportunities than those suburban recipients without such barriers. We also found the co-occurrence of barriers to employment to vary spatially. In particular, our findings indicate that welfare recipients living in the City of Detroit, where over $90 \%$ of the region's caseload resides, were more likely to experience co-occurring barriers than were recipients in most of the suburban areas around the city.

Prevalence rates for many barriers to employment also varied within race groups by location. Among MWS respondents, suburban Whites were most likely to experience mental health barriers to employment, whereas suburban African Americans were most likely to experience both substance abuse and domestic violence barriers to employment. Although sample sizes are small, it appears that cooccurring barriers to employment were more common among White and African American recipients in the central city than among those recipients living in areas outside the city. Just as there is not one descriptive story of barriers to employment across a single metropolitan area like Detroit, there is not likely to be one story of barriers to employment that fits all African Americans and Whites in a given metropolitan area.

Although this study can only report prevalence rates of barriers to employment for one city in a cross-section, we believe our simple descriptive account strongly points to the need for additional research examining the linkages among place, barriers to employment, and program outcomes. Just as policy scholars and analysts are often critical of policymakers for approaching welfare-to-work as if it were being implemented on a featureless plane where geographic variation is inconsequential, empirical research should push toward a better understanding of how place matters to the implementation of welfare reform and to the observed outcomes of welfare-to-work programs. Many studies are unable to capture the subtle, but important, variation among urban, suburban, and rural jurisdictions within a given region or area. Ultimately, research that cannot capture the interactions between place and the individual may misidentify or overstate the importance of either factor. As a result, greater emphasis should be placed on finding data that can examine caseload characteristics, program features, and work outcomes across different geographic locations.

Further, with over half of all TANF expenditures today targeted at support services (U.S. Department of Health and Human Services, 2002; U.S. General Accounting Office, 2001, 2002b), our findings suggest that program managers should continue to ensure a proper fit between the supply of and demand for social services. Not only does this mean instituting processes for screening and referring clients to appropriate service providers, but it means continually working with local governmental and nongovernmental service providers to ensure a match 
between the changing nature of service supply and the changing nature of service demands. In addition to intrametropolitan variation in the prevalence of barriers to employment, it seems quite plausible that significant intrastate variation in the prevalence of barriers to employment may be present. And since welfare caseloads are now more dynamic in composition than they were prior to welfare reform, it is important for program managers and policymakers to be alert to temporal, as well as spatial, variation in the presence of barriers to employment.

Given the substantial caseload reductions of the 1990s, there is concern that the remaining welfare caseload will become composed of increasingly harder-toserve clients with multiple co-occurring barriers to employment. Since over 90\% of the welfare caseload in the Detroit metropolitan area continues to reside within the central city, as is typical in major urban areas (Allen \& Kirby, 2000), the prevalence of co-occurring barriers in the central city highlights complex needs of urban welfare recipients and the challenges facing program managers operating in urban areas with limited resources and flexibility. Although states may be able to exempt many of these hard-to-serve cases from federal welfare time limits, welfare program managers must still seek support service strategies that will facilitate selfsufficiency among those with co-occurring barriers in the long-term. Bundling social services appropriate for recipients struggling with multiple barriers to employment will likely remain a common approach to helping hard-to-serve cases conduct work activity. Other strategies might involve expanding the definition of work activity to include participation in activities designed to address barriers to employment and providing postemployment services to address barriers to employment that persist or recur (Goldberg, 2002).

As program managers and policymakers continue to seek effective strategies for coordinating a wide array of services to support work, communication and information-sharing networks should better link welfare recipients to service providers, better track client referrals, and better ascertain whether assistance was received by a referred client. The urban geography of barriers to employment uncovered here strongly suggests that welfare-to-work programs should have greater flexibility in the screening and assessment of welfare recipients to enable caseworkers to better support work activity. Performance benchmarks and incentives also should take into account local-level variation, rewarding those areas or offices that demonstrate success at treating particularly hard-to-serve clients. Even in the current policy environment, however, work-first programs that consider how well support services and employment opportunities converge spatially in communities to help welfare recipients overcome barriers to employment are likely to be more successful in the long-term than those programs that do not consider the geographic realities of welfare-to-work.

Scott W. Allard is an assistant professor of political science and public policy at Brown University. His research is focused on understanding spatial variation in welfare-to-work program outcomes and on the evolution of subnational welfare programs during the emergence of the modern American welfare state. 
Richard M. Tolman is a professor of social work and associate dean for Educational Programs at the University of Michigan, School of Social Work. His research focuses on trauma, violence, and mental health and on the economic impact of these issues in the lives of low-income women.

Daniel Rosen is an assistant professor of social work at the University of Pittsburgh. His research focuses on understanding access to and utilization of mental health and substance abuse services in low-income populations.

\section{Notes}

1. This project was supported in part by a grant from the U.S. Department of Health and Human Services, Office of the Assistant Secretary for Planning and Evaluation, grant number 00ASPE356A, and by the National Institute of Mental Health, grant number R24-MH57943-01. The opinions and conclusions expressed herein are solely those of the authors and should not be construed as representing the opinions of any agency of the Federal Government. The authors would like to thank Sheldon Danziger for comments on previous drafts.

2. The survey sample was selected from administrative records provided by the State of Michigan Family Independence Agency (FIA) indicating all individuals receiving welfare in September 1998 in Wayne, Oakland, and Macomb counties. Using information from the administrative records, the sample was limited to African American and White women aged 18 to 54. Noncitizen, non-English speaking, and/or two-parent households were excluded. Of the 859 women randomly selected from FIA administrative records meeting these criteria, 668 were interviewed by telephone, for an overall response rate of nearly $78 \%$.

3. See Danziger et al. (2000), Jayakody and Stauffer (2000), Lennon et al. (2001), and Lutenbacher (2000) for a discussion of these mental health screening criteria.

4. Domestic violence was assessed with a modified version of the Conflicts Tactics Scale (CTS) (see Straus, 1979). We augmented the CTS by adding items that asked about additional physical and nonphysical forms of abusive behavior. These domestic violence items were used to create 12month and lifetime prevalence measures.

5. To estimate the proximity of residential tracts to employment opportunities, we created tract-level employment access measures from a 1992 survey by the Multi-City Survey of Urban Inequality (MCSUI) and a follow-up survey by Harry Holzer of the Urban Institute in 1997. In each survey, employers were asked for information on the total number of employees at the time of the interview and how the size of the firm's workforce had changed in the previous year. Each survey represents a random sample of employers in the Detroit metropolitan area and an accurate representation of employment opportunities. See Allard (2002) for details as to how our accessibility measures were calculated.

6. Note that the findings reported here are weighted using a survey weighting scheme developed for the MWS.

7. MWS respondents had access to $2.3 \%$ fewer jobs than the average residential tract.

8. MWS respondents on average had access to 2.6\% fewer jobs in 1997 than in 1992.

9. Although not reported because of small sample sizes, the bottom panel of Table 2 indicates that many of these patterns persist when looking at racial differences within a particular county.

10. See Ihlandfeldt and Sjoquist (1998) for a review of the job access and spatial mismatch literature.

\section{References}

Allard, M. A., Albelda, R., Colten, M. E., \& Cosenza, C. (1997). In harm's way? Domestic violence, AFDC receipt and welfare reform in Massachusetts. Boston: University of Massachusetts, McCormack Institute http://www.mccormack.UMB.EDU/csp/publications/harms\%20way.pdf. 
Allard, S. W. (2002). The urban geography of welfare reform: Spatial patterns of caseload dynamics in Detroit. Social Science Quarterly, 83(4), 1044-1062.

Allard, S. W., \& Danziger, S. (2003). Proximity and opportunity: How residence and race affect welfare recipients." Housing Policy Debate, 13(4), 675-700.

Allen, K., \& Kirby, M. (2000). Unfinished business: Why cities matter to welfare reform. Washington, D C: Center on Urban and Metropolitan Policy, The Brookings Institution.

Barusch, A., Taylor, M. J., Derr, M., \& Abu-Bader, S. (1999). Understanding families with multiple barriers to self-sufficiency. Manuscript submitted to Utah Department of Workforce Services, Salt Lake City, Social Research Institute, University of Utah.

Browne, A., Salomon, A., \& Bassuk, S. (1999). Impact of recent partner violence on poor women's capacity to maintain work. Violence Against Women, 5(4), 393-426.

Danziger, S., et al. (2000). Barriers to the employment of welfare recipients." In R. Cherry \& W. Rodgers, (Eds.), The impact of tight labor markets on Black employment problems (pp. 245278). New York: Russell Sage Foundation.

Danziger, S., \& Seefeldt, K. (2002). Barriers to employment and the "hard to serve": Implications for services, sanctions, and time limits. Focus, 22(1), 76-81.

Goldberg, H. (2002). Improving TANF Program outcomes for families with barriers to employment. Washington, DC: Center for Budget and Policy Priorities.

Grant, B. F., \& Dawson, D. (1996). Alcohol and drug use, abuse, and dependence among welfare recipients. American Journal of Public Health, 86(10), 1450-1454.

Holzer, H. J., \& Stoll, M. A. (2001). Meeting the demand: Hiring patterns of welfare recipients in four metropolitan areas. Washington DC: Center on Urban and Metropolitan Policy, The Brookings Institution.

Ihlandfeldt, K. F., \& Sjoquist, D. L. (1998). The Spatial Mismatch Hypothesis: A review of recent studies and their iImplications for welfare reform. Housing Policy Debate, 9(4), 849-892.

Jayakody, R., Danziger, S., \& Pollack, H. (2000). Welfare reform, substance abuse, and mental health. Journal of Health Politics, Policy, and Law, 25(4), 623-651.

Jayakody, R., \& Stauffer, D. (2000). Mental health problems among single mothers: Implications for work and welfare reform. Journal of Social Issues, 56, 617-634.

Kalil, A., Schweingruber, H. A., \& Seefeldt, K. S. (2001). Correlates of employment among welfare recipients: Do psychological characteristics and attitudes matter?" American Journal of Psychology, 29(5), 701-723.

Lennon, M. C., Blome, J., \& English, K. (March 20, 2001). Depression and low-income women: Challenges for TANF and welfare-to-work policies and programs. Research Forum on Children, Families, and the New Federalism. Retrieved from http://www.researchforum.org.

Lutenbacher, M. (2000). Perceptions of health status and the relationship with abuse history and mental health in low-income single mothers. Journal of Family Nursing, 6(4), 320-340.

Polit, D., London, A., \& Martinez, J. (May 25, 2001). The Health of Poor Urban Women: Findings from the Project on Devolution and Urban Change." Manpower Demonstration Research Corporation. Retrieved from http://www.mdrc.org/Reports2001/UC-HealthReport/UC-HealthRpt FullRpt2001.pdf.

Straus, M. A. (1979). "Measuring Intrafamily Conflict and Violence: The Conflict Tactics (CT) Scales." Journal of Marriage and the Family, 41, 75-88.

Tolman, R. M., \& Raphael, J. (2000). A review of research on welfare and domestic violence. Journal of Social Issues, 56(4), 655-682.

Tolman, R. M., \& Rosen, D. (2001). Domestic violence in the lives of welfare recipients: Mental health, health and economic well-being." Violence Against Women, 7(2): 141-158.

U.S. Department of Health and Human Services, Office of Inspector General. (February 26, 2002). State strategies for working with hard-to-employ TANF recipients. Retrieved from http://oig.hhs.gov/oei/reports/oei-02-00-00630.pdf. 
U.S. General Accounting Office. (2001). Welfare reform: Moving hard-to-employ recipients into the workforce (GAO-01-368).

U.S. General Accounting Office. (2002a). Welfare reform: Former TANF recipients with impairments less likely to be employed and more likely to receive federal supports (GAO-03-210), http://www.gao.gov.

U.S. General Accounting Office. (2002b). Welfare reform: States provide TANF-funded services to many low-income families who do not receive cash assistance (GAO-02-564).

Zedlewski, S. R., \& Alderson, D. W. (2001). Before and after reform: How have families on welfare changed? Washington, DC: The Urban Institute. 
Copyright $\odot 2003$ EBSCO Publishing 
This document is a scanned copy of a printed document. No warranty is given about the accuracy of the copy. Users should refer to the original published version of the material. 